\title{
DEVELOPMENT AND INTEGRATION OF INTELLIGENT, VOICE STRESS ANALYSIS AND IRIS RECOGNITION TECHNOLOGIES IN CONSTRUCTION
}

\author{
Edmundas Kazimieras Zavadskas \\ First vice-rector of Vilnius Gediminas \\ Technical University, Vilnius Gediminas \\ Technical University, Sauletekio al. 11, LT- \\ 2040 Vilnius, Lithuania, e-mail: \\ edmundas.zavadskas@adm.vtu.lt
}

\author{
Arturas Kaklauskas \\ Chairman of Department of Construction Economics \\ and Real Estate Management \\ Vilnius Gediminas Technical University, Sauletekio \\ al. 11, LT-2040 Vilnius, Lithuania, \\ Arturas.Kaklauskas@st.vtu.lt
}

\begin{abstract}
Intelligent systems (neural networks, expert, knowledge, decision support and other systems) in construction can be used on the national, organization and project levels. However, most of all neural networks, knowledge, decision support and expert systems are seeking to find how to make the most economic construction decisions, and most of all these decisions are intended only for economic objectives. Also currently voice stress analysis, digital physiognomy and IRIS recognition technologies are very seldom used in construction. Development and integration of some intelligent, voice stress analysis and IRIS recognition technologies in construction by Vilnius Gediminas Technical University since 1984 are described in the paper.
\end{abstract}

\section{KEYWORDS}

Intelligent, Voice Stress Analysis and IRIS Recognition Technologies, Construction, Development and Integration.

\section{INTRODUCTION}

Construction intelligent systems can be used on the national [5, 16, 17], organization [5] and project $[1,3,4,6,18,19]$ levels.

On the national level intelligent technologies enables one to find and analize the required data quickly and from various perspectives, as well as allowing effective communication between interested parties for making important decisions at a distance. Intelligent technologies at country or European levels have been analyzed and written about in a variety of research literature.

On the organizational level intelligent technologies are used to get and process the data on financing and investment possibilities as well as on real estate (GIS - Geographical Information System), government-provided services, producers and their products (intelligent electronic catalogues), etc. For example, organizations get the possibility to search for most suitable suppliers, contractors and use market offers for the best advantage. Intelligent technologies also provide the opportunities for learning and qualification improvement (by distance learning, the availability of intelligent electronic libraries).

On the project level the use of intelligent systems (i.e. expert, decision-support systems, etc.) allows all the interested parties, (i.e. designers, economists, architects, builders, facilities management personel) to solve the problems concerning the life time of a building (including brief, design, construction, maintenance, facilities management and demolishing stages). For this purpose data bases are being created embracing the data and knowledge obtained from the previously made similar projects as well as the experience of experts and the data contained in various norms, standards and other sources of information. 
However, most of all neural networks, decision support and expert systems are seeking to find how to make the most economic construction decisions, and most of all these decisions are intended only for economic objectives. Quite a number of decision making methods (including all multiple criteria decision making methods) may make integrated analyses of many indicators of different dimensions. However, for various reasons they are not made by many computer systems developed in the construction branch. Also currently voice stress analysis, digital physiognomy and IRIS recognition technologies are quite seldom used in construction. Above partly in construction missing technologies have been applied by authors with their associates.

\section{WEB-BASED INTELLIGENT, VOICE STRESS ANALYSIS AND IRIS RECOGNITION SYSTEMS}

Web-based intelligent, voice stress analysis and IRIS recognition systems in construction developed by authors in cooperation with their associates are as follows:

- Building's Refurbishment Knowledge and Device Based Decision Support System [9, $10,20,25]$,

- Innovation Multiple Criteria Decision Support Web-Based System [26],

- Multiple Criteria On-Line International Trade Decision Support System [7, 26],

- Multiple Criteria Decision Support WebBased System for Facilities

Management [7],

- Cooperative Integrated Web-based Negotiation Decision Support System for Real Estate [12, 13],

- Multiple Criteria Decision Support On-Line System for Construction Products [8],

- Sustainable Development Analysis WebBased System [26],

- Intelligent Library and Tutoring System [15],

- Voice Stress Analysis System [13],

- IRIS Recognition System [13]
- Ethical Multiple Criteria Decision Support Web-Based System [11],

- Building Life Cycle Decision Support System [2, 22, 23, 24],

- Loan Analysis Decision Support System [21],

- Foundations Analysis Decision Support System [22, 24],

- Buildings' Multivariant Design and Multiple Criteria Analysis Decision Support System [22, 24], etc.

Then the brief study of authors with their associates some of above developed voice stress analysis and IRIS recognition systems follows.

\section{PRACTICAL APPLICATIONS OF VOICE STRESS ANALYSER SUBSYSTEMS}

The Voice Stress Analyser (VSA) Subsystem measures stress in a human voice. VSA Subsystem can be used for analysis of different situations in construction (work of brokers, analysis of stakeholders' subjective opinions about pollution and health effects, e-learning, etc.). Statistical information database was developed in order to efficiently use VSA Subsystem in practice.

The practical application of the VSA Subsystems in sales of real estate and e-learning are briefly analyzed as follows.

\subsection{VSA Subsystem in Sales of Real Estate}

A typical situation of a first visit to an apartment was selected. The discussion between the seller and the broker inspecting an apartment for sale was recorded (consent from both). Standard questions were asked during the conversation. Advantages and disadvantages of an apartment were detected, the sales price established, as well as the size of the broker's commission and negotiations on conclusion of a mediation agreement. The VSA Subsystem analyses record shows the vibration curve of a sound document, which indicates the sound frequency in real time. If a sound frequency is high, the oscillation of the sound curve is denser. Such density of oscillations of a sound curve shows that a person is not sure of the correctness of his/her statement or conceals some truth. For example, it was noticed that a 
sound vibration curve typically is very dense when a client speaks about the brokering contract. Evidence provided by the VSA Subsystem can show whether a client's statement is false or doubtful.

The research determined that people are usually unsure or conceal part of truth when speaking about brokering contract, exact floor area of an apartment, furniture for sale with the apartment, sale's price of the apartment, and remuneration to a broker, etc. All these criteria are essential in the activities of a broker. False information may leave a broker without remuneration for the work. Knowledge that a client is lying when he/she speaks about such things can also protect a broker against fraud. Currently, when sufficient statistical information is not available yet, it would be wrong to rely on evidence provided only by the VSA Subsystem. However, it can help to avoid a number of misunderstandings and other problems.

A company can use the VSA Subsystem for its specific purposes, e.g. at conferences, during reports to a top manager and at other meetings. Thus the head of a company will have an opportunity to analyse the information, requests and opinions, etc. provided at a meeting and to make decisions on the basis of the evidence of the VSA Subsystem as well as the manager's logical thinking. Such application of the system would not be difficult, because internal regulations of a company allow a head to collect and use information about the company's personnel. Besides, the obtained information would help to meet client's needs and the company's employee's needs in better ways.

As example, a relationship between the deviation from the real area of apartment deliberately increased by the seller (in per cent) and the average microtremor frequency of the voice when claiming bigger floor area is presented in Figure 1. The $\mathrm{x}$-axis shows the deviation (in per cent) of the increased area of the apartment (compared to the real) specified by the seller during the conversation. The y-axis shows the scale of the average microtremor frequency noticed in the seller's voice during the conversation. Besides, the Figure 1 clearly shows the relationship between the level of untruth told by the seller and the average microtremor frequency. The higher the average microtremor frequency the more area is added to the real area of an apartment.

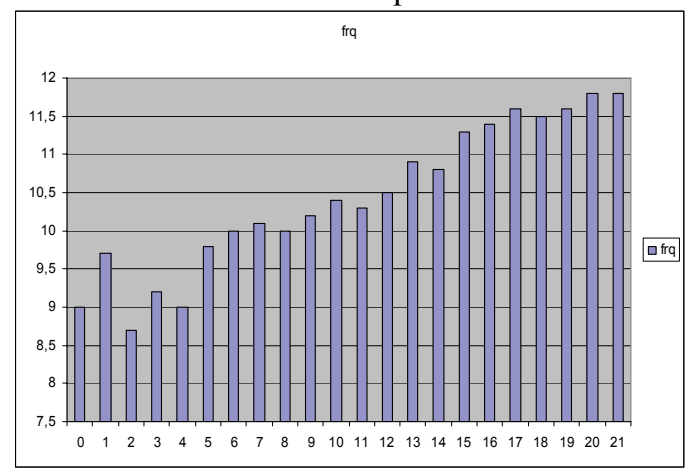

Figure 1 The Relationship Between the Deviation from the Real Area of Apartment Deliberately Increased by the Seller (in per cent) and the Average Microtremor Frequency of the Voice when Claiming Bigger Floor Area

In the nearest future there will be a possibility to assess correctness of provided information (in \%) automatically by using VSA Subsystem on the basis of accumulated historic statistical data and determined regression equations. For example, according to a seller's answer about the floor area of an apartment, the VSA Subsystem would automatically convert the answer into frequency and specify the actual floor area of an apartment and the percentage of deviation from the floor area of the apartment as specified by a buyer.

\subsection{VSA Subsystem in e-Learning}

The research aim was to compare data received during an examination with ILTS-BP (information on correct and incorrect answers, time periods for each question, and the number of times a student changed an answer to each question of a test) with similar data received from the Voice Stress Analyser (VSA) Subsystem, to make practical conclusions and to plan future research. This research helped to determine changes of students' psychophysical conditions during examination. During an e-test, students were asked to select one correct answer from the provided alternatives and to say the answer aloud. The sound record of each answer was then saved into a PC memory with an identification code for listening and further analysis. Records were analysed by using the VSA Subsystem and the frequency range of micro-tremors for each specific answer to an e-test question was determined. The higher frequency of 
voice vibrations was determined when analysing voice answers to "unknown/difficult" questions. It was found that the emotional stress of a student was higher when answering "unknown/difficult" questions.

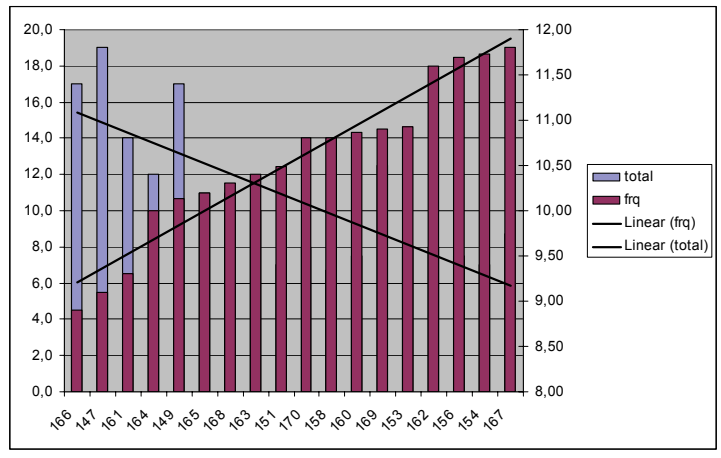

\section{Figure 2 Correlation of Relationships Between Emotional Stress and Correct/Incorrect Answers to an e-Test}

The reliability of the results was assessed by making a correlation analysis of emotional stress and of evaluations of correct/incorrect answers to test questions. The analysis showed that a correlation exists between emotional stress and the correctness of an answer. During the experiment, a total of 4,000 voice records in four student groups were examined and analysed. The research helped to determine whether questions can be classified (in respect to students) as "known/simple", "unknown/difficult" and remaining questions inbetween these two groups. The "unknown/difficult" experienced higher than average emotional stress, and zero or minor emotional stress when answering "known/simple" questions. On analysis of the whole set of answers, a direct relationship was noticed between emotional stress and correct/incorrect answers to an e-test, i.e. answers to "unknown/difficult" questions scored less than answers to "known/simple" questions (see Fig. 2). During the research, the average microtremor was calculated for each question. Part of the results is shown in Figure 2.

Figure 2 shows the relation between a student's grade and the average microtremor frequency of the answers to test questions. The $\mathrm{x}$-axis shows ID numbers of students who were passing the examination. During examination students had to mark and to say aloud the right answers to 20 questions within 10 minutes. The left side of the yaxis shows the scale of points received by each student. A student who correctly answered all questions could get a maximum of 20 points. The right side of the $y$-axis shows the average microtremor frequency of each student during the examination. Besides, the Figure 2 shows two correlating curves obtained during the research; they show the direct relationship between the grade and the average microtremor frequency. For instance, the higher is the average microtremor frequency the worse is the grade. And vice versa.

As seen from the data in Fig. 2, a student can be assessed according to the regression relationship between emotional stress and correct/incorrect answers to e-tests. On the development of a more exhaustive database of voice analysis such evaluations will become more precise. For example, when a teacher gives a student such questions as "Are you well-prepared for the exam?, What mark would you give to your knowledge?, and Have you learnt everything?" before an examination, the VSA Subsystem determines the average micro-tremor of the answers, and the student can be assessed precisely by being given a mark.

In the future there will be a possibility to assess students' knowledge automatically by using VSA Subsystem on the basis of accumulated historic data and determined regression equation. For example, the VSA Subsystem will automatically assess a student's knowledge during an examination according to the student's spoken/oral answers, i.e. the VSA Subsystem will convert student's answers into $\mathrm{Hz}$ and the IITS will show a mark according to the amount of Hz. solutions.

\section{IRIS RECOGNITION TECHNOLOGIES IN E-LEARNING}

An IRIS Recognition Subsystem using the analogy of the Voice Stress Analyser Subsystem is being developed. Similarly to the Voice Stress Analyser Subsystem, the IRIS recognition technology can show the relation between changes of the eye's pupil and the emotional condition of a person. The IRIS Recognition Subsystem uses technology to identify features particular to each student's eye. The IRIS Recognition Subsystem is technology for the measurement of human physiological or 
behavioural features. Current research is searching for a relationship between the change of an iris' diameter and the emotional condition. During research, a micro-camera is mounted in front of a student; the camera records changes of the diameter of the student's iris and passes the data to a PC. Special software takes pictures of the iris every three seconds and saves the results into a PC's hard-drive in separate files. By using the Matlab software and accessory scripts, the diameter of the iris is calculated by using the pictures, and the determined changes are saved into a database. For a final result, a database which keeps students' answers to questions and the information about change of the diameter of the iris during examination (every three seconds) was developed.

A student can be assessed according to the regression relationship between emotional stress and correct/incorrect answers to e-tests. On the development of a more exhaustive database of IRIS Recognition such evaluations will become more precise. For example, when a teacher gives a student such questions as "Are you well-prepared for the exam?, What mark would you give to your knowledge?, and Have you learnt everything?" before an examination, the IRIS Recognition Subsystem will automatically assess the student's knowledge according to the average number of changes in the student's iris and on the basis of the accumulated data and determined causal relationships. In the future there will be a possibility to assess students' knowledge automatically by using IRIS Recognition Subsystem on the basis of accumulated historic data and determined regression equation.

\section{CONCLUSIONS}

Since 1984 various intelligent, voice stress analysis and IRIS recognition (Building's Refurbishment, Innovation, International Trade Decision, Facilities Management, Real Estate, Construction Products, Sustainable Development, Intelligent Library and Tutoring System, Voice Stress Analysis, IRIS Recognition, Air Pollution and Health Impact, Ethical, Building Life Cycle, Loan, Foundations, Buildings' Multivariant Design and Multiple Criteria Analysis, etc.) systems in construction developed by authors in cooperation with their associates in Vilnius Gediminas Technical University.

\section{REFERENCES}

[1] Alshawi, M. \& Ingirige, B. (2003) Web-enabled Project Management: an Emerging Paradigm in Construction, Automation in construction, Vol. 12, No. 4, 349-364.

[2] Banaitiene, N., Banaitis, A., Kaklauskas, A. \& Zavadskas E. K. (2008) Evaluating the life cycle of a building: A multivariant and multiple criteria approach, Omega, Vol. 36, Issue 3, 429-441

[3] Cheung, S., Suen, H. C. H. \& Cheung, K. K. W. (2004) PPMS: a Web-based Construction Project Performance Monitoring System, Automation in construction, Vol. 13, No. 3, 361-376.

[4] Emerging Construction Technologies. Hybrid Computerized Decision Support System for Infrastructure Assessment (2004) http://www.newtechnologies.org/ECT/Other/imageprocess.htm

[5] Hassan, T. M. \& McCaffer, R. (2002) Vision of the Large Scale Engineering Construction Industry in Europe. Automation in Construction, Vol. 11, No. 4, 421-437.

[6] Husin, R. \& Rafi, A. (2003) The Impact of Internetenabled Computer-aided Design in the Construction Industry, Automation in Construction, Vol. 12, No. 5, 509-513.

[7] Kaklauskas, A. \& Zavadskas, E. (2002) Web-Based Decision Support, Technika, Vilnius, 292.

[8] Kaklauskas, A., Zavadskas, E. K. \& Trinkunas, V. (2007) A multiple criteria decision support on-line system for construction, Engineering Applications of Artificial Intelligence, Vol. 20, Issue 2, 163-175.

[9] Kaklauskas, A., Zavadskas, E. K., Raslanas, S., Ginevicius, R., Komka, A. \& P. Malinauskas (2006) Selection of low-e windows in retrofit of public buildings by applying multiple criteria method COPRAS: A Lithuanian case. Energy and Buildings, Vol. 38, Issue 5, 454-462.

[10] Kaklauskas, A., Zavadskas, E. K. \& Raslanas, S. (2005) Multivariant design and multiple criteria analysis of building refurbishments, Energy and Buildings, Vol. 37, Issue 4, 361-372.

[11] Kaklauskas, A. \& Pruskus, V. (2005) The Uses of Internet in the Ethical Multiple Criteria DecisionMaking, Problemos, Vol. 68, 109-127.

[12] Kaklauskas, A., Zavadskas, E. K. \& Andruškevičius, A. (2005) Cooperative integrated web-based negotiation and decision support system for real estate, Lecture Notes in Computer Science. .Cooperative Design, Visualization, and Engineering: Second International Conference, 
CDVE 2005, Palma de Mallorca, Spain, September 18-21, 2005 : proceedings. Vol. 3675, 235-242.

[13] Kaklauskas, A., Vlasenko, A., Krutinis, M. \& Remezaite L. (2007) Integration of Intelligent Tutoring, VSA and IRIS Recognition Technologies in Real Estate, International conference "Economy, valuation and management of real estate and natural resources", Proceedings, Minsk, April 18$20,119-130$

[14] Kaklauskas, A., Zavadskas, E., Babenskas, E., Seniut, M., Vlasenko, A. \& Gulbinas, A. (2007) Intelligent Library and Tutoring System for Brita in PuBs Project, Lecture Notes in Computer Science. Cooperative Design, Visualization, and Engineering: Fourth International Conference, CDVE 2007, (In Press).

[15] Kaklauskas, A., Ditkevičius, R. \& Gargasaitè L. (2006) Intelligent tutoring system for real estate management, International Journal of Strategic Property Management, Vilnius: Technika, Vol. 10, No. 2, 113-130.

[16] Liao, T. S., Wang, M. T. \& Tserng, H. P. (2002) A Framework of Electronic Tendering for Government Procurement: a Lesson Learned in Taiwan, Automation in construction, Vol. 11, No. 6, 731-742.

[17] McCaffer, R. \& Hassan, T.M. (2000) Changes in Large Scale Construction Arising from ICT Developments, Proceedings of the Millennium Conference on Construction Project Management, Hong Kong Institution of Engineers, Hong Kong, $8-15$.

[18] Mohan, S. (1990) Expert Systems Application in Construction Management and Engineering. Journal of Construction Engineering and Management, Vol. 116, No. 1, 87-99.
[19] Nobe, M. D., Sharkawy, M. A. \& Nobe, M. C. (1999) Decision Support System Impact on Conceptual Cost Estimating and Risk Analysis. ASC Proceedings of the 35th Annual Conference, California Polytechnic State University - San Luis Obispo, California. April 7 - 10, 1999. pp 335 348.

[20] Zavadskas, E., Raslanas, S. \& Kaklauskas, A. The selection of effective retrofit scenarios for panel houses in urban neighborhoods based on expected energy savings and increase in market value: The Vilnius case, Energy and Buildings, doi: 10.1016/j. enbuild. 2007.04.015

[21] Zavadskas, E. K., Kaklauskas, A., Banaitis, A. \& Kvederyte N. (2004) Housing credit access model: The case for Lithuania, European Journal of Operational Research, Vol. 155, Issue 2, 335-352.

[22] Zavadskas, E. K., Peldschus, F \& Kaklauskas, A., (1994) Multiple Criteria Evaluation Projects in Construction. Technika, Vilnius. 226.

[23] Zavadskas, E. K., Kaplinski, O., Kaklauskas A. \& Brzezinski, J., (1995) Expert Systems in Construction. Trends, Potential \& Applications, Technika, Vilnius. 180.

[24] Zavadskas, E. K. \& Kaklauskas, A. (1996) Multiple criterion analysis of projects in construction. Technika, Vilnius. 280

[25] Zavadskas, E. K., Simanauskas, L. \& Kaklauskas, A., (1998) Decision support systems in construction, Technika, Vilnius. 236

[26] Zavadskas, E. K. \& Kaklauskas, A., (2000) Efficiency Increase in Research and Studies While Applying up-to-date Information Technologies. Journal of Civil Engineering and Management (Statyba), Vol. 6, No. 6, 397-414. 